\title{
Revascularisation and mortality rates following acute coronary syndromes in people with severe mental illness: comparative meta-analysis
}

\author{
Alex J. Mitchell and David Lawrence
}

\section{Background}

High levels of comorbid physical illness and excess mortality rates have been previously documented in people with severe mental illness, but outcomes following myocardial infarction and other acute coronary syndromes are less clear.

\section{Aims}

To examine inequalities in the provision of invasive coronary procedures (revascularisation, angiography, angioplasty and bypass grafting) and subsequent mortality in people with mental illness and in those with schizophrenia, compared with those without mental ill health.

\section{Method}

Systematic search and random effects meta-analysis were used according to the Preferred Reporting Items for Systematic Reviews and Meta-Analyses guidelines. Studies of mental health and cardiovascular procedures following cardiac events were eligible but we required a minimum of three independent studies to warrant pooling by procedure type. We searched Medline/PubMed and EMBASE abstract databases and ScienceDirect, Ingenta Select, SpringerLink and Online Wiley Library full text databases.

\section{Results}

We identified 22 analyses of possible inequalities in coronary procedures in those with defined mental disorder, of which 10 also reported results in schizophrenia or related psychosis. All studies following acute coronary syndrome originated in the USA. The total sample size was 825754 individuals. Those with mental disorders received 0.86 (relative risk, RR: $95 \% \mathrm{Cl} 0.80-0.92, P<0.0001$ ) of comparable procedures with significantly lower receipt of coronary artery bypass graft (CABG; RR $=0.85,95 \% \mathrm{Cl} 0.72-1.00$ ), cardiac catheterisation ( $\mathrm{RR}=0.85,95 \% \mathrm{Cl} 0.76-0.95)$ and percutaneous transluminal coronary angioplasty or percutaneous coronary intervention (PTCA/PCl; RR $=0.87$, $95 \% \mathrm{Cl}$ 0.72-1.05). People with a diagnosis of schizophrenia received only $0.53(95 \% \mathrm{Cl} 0.44-0.64, P<0.0001)$ of the usual procedure rate with significantly lower receipt of CABG $(\mathrm{RR}=0.69,95 \% \mathrm{Cl} 0.55-0.85)$ and PTCA/PCl $(\mathrm{RR}=0.50,95 \% \mathrm{Cl}$ $0.34-0.75)$. We identified 6 related studies examining mortality following cardiac events: for those with mental illness there was a 1.11 relative risk of mortality up to 1 year (95\% Cl 1.00-1.24, $P=0.05$ ) but there was insufficient evidence to examine mortality rates in schizophrenia alone.

\section{Conclusions}

Following cardiac events, individuals with mental illness experience a $14 \%$ lower rate of invasive coronary interventions ( $47 \%$ in the case of schizophrenia) and they have an $11 \%$ increased mortality rate. Further work is required to explore whether these factors are causally linked and whether improvements in medical care might improve survival in those with mental ill health.

\section{Declaration of interest}

None.
Coronary heart disease is the leading cause of death worldwide. ${ }^{1,2}$ Acute coronary syndrome refers to acute myocardial ischaemia caused by atherosclerotic coronary disease and includes myocardial infarction and unstable angina. Patients with ST elevation myocardial infarction are recommended for immediate reperfusion therapy using thrombolytic agents or percutaneous coronary intervention (PCI). ${ }^{3,4}$ From 1980 to 1990 there was a $34 \%$ decline in coronary heart disease mortality in the USA. ${ }^{5}$ Over the same period there was a substantial growth in the number of cardiovascular procedures performed, particularly PCI. Improvements in the quality of care are thought to be a major factor underlying declining mortality. ${ }^{5}$ Yet despite these improvements evidence of sociodemographic inequalities in procedural rates has been accumulating. ${ }^{6-11}$ Inequalities have also been documented with regard to the medical care of those with known mental health diagnoses. Medical care includes medical treatment and processes of care such as investigations and monitoring. Mitchell et al evaluated 27 studies that examined receipt of medical care in those with and without mental illness (including 11 studies of severe mental illness or schizophrenia and 10 of dual diagnosis or substance use disorder). ${ }^{12}$ The majority of studies demonstrated significant inequalities in receipt of quality of care including 7 of 10 studies that examined the quality of cardiovascular care. Lord et al recently reviewed 25 studies that examined preventive care in individuals with or without psychiatric illness; for individuals with schizophrenia, 8 of 9 analyses suggested inferior receipt of preventive care in several areas including blood pressure monitoring, vaccinations, mammography and cholesterol monitoring. ${ }^{13}$ From these narrative reviews it is clear that the magnitude of the deficits in quality of care varies considerably depending on the setting and method of data collection.

There is substantial concern about the cardiovascular health of those with known mental health diagnoses, especially severe mental illness and schizophrenia. ${ }^{14,15}$ National guidelines from several countries are agreed that the medical care of patients with mental disorders is of paramount importance. ${ }^{16-19}$ However, serious concerns have been raised about the quality of medical care offered to patients with severe mental illness. People with schizophrenia have higher rates of several important conditions including the metabolic syndrome. ${ }^{20,21}$ Most studies, ${ }^{15,22-28}$ but not all, ${ }^{29,30}$ suggest that incidence of cardiovascular disease is higher in people with schizophrenia. Such individuals often have higher than expected rates of contributing background risk factors including smoking, ${ }^{31}$ obesity ${ }^{32}$ dyslipidaemia, ${ }^{33}$ lack of exercise, ${ }^{34}$ and possibly essential hypertension. ${ }^{35}$ A meta-analysis suggested a relative risk of 1.87 (95\% CI 1.68-2.09) for diabetes in schizophrenia, but with no significant elevation of hypertension 
or cholesterol. ${ }^{36}$ Of these factors, smoking and obesity may be most critical to future cardiovascular health. ${ }^{37}$ An estimated $42 \%$ of patients with schizophrenia have a body mass index above $27 \mathrm{~kg} / \mathrm{m}^{2}$ compared with $27 \%$ among the general US population; ${ }^{15}$ three-quarters are regular cigarette smokers compared with a quarter of the general population. ${ }^{15}$ It is therefore probably not surprising that people with schizophrenia have higher than expected non-suicide-related mortality; in fact, mortality from comorbid physical illness outnumbers the excess mortality from suicide. ${ }^{38}$ A systematic review of 37 studies found that that those with schizophrenia have a 2.6 times greater rate of mortality compared with the general population, including 1.8 times the mortality rate from cardiovascular disease. ${ }^{39}$

Given these numerous concerns regarding cardiovascular health in severe mental illness and in particular in schizophrenia, we aimed to examine and quantify, first, the receipt of medical procedures following acute coronary syndrome, and second, the mortality rate following acute coronary syndrome using metaanalysis of published data. We were interested in comparative studies that examined the adequacy of appropriate procedures and subsequent mortality for people with cardiac disorders stratified into those with and without severe mental illness/schizophrenia.

\section{Method}

\section{Search}

We used the Preferred Reporting Items for Systematic Reviews and Meta-Analyses (PRISMA) guidelines, a checklist of 27 items that ensure the quality of systematic review or meta-analysis. ${ }^{40}$ Inclusion criteria were studies of patients with acute coronary syndromes (with data on rates of subsequent invasive coronary procedures or mortality) which reported data for those with defined mental illness as well as those without mental ill health. We only included those with severe mental illness provided there was a subgroup with schizophrenia. We excluded noncomparative studies, and also those concerning depression or anxiety only. We searched Medline/PubMed and EMBASE abstract databases from inception to 20 July 2010. In these databases the keywords/MeSH terms ('ACS or REVASCULARISATION or REVASCULARIZATION or PROCEDURES or GRAFT or ANGIOPLASTY or PERCUTANEOUS or CATHETERIZATION or CARDIA* or HEART') and ('PSYCHI* ${ }^{*}$ or MENTAL or PSYCHOSIS or PSYCHOTIC or SCHIZOPHR ${ }^{*}$ or SEVERE MENTAL ILLNESS or SMI') were used. In addition, four full text collections were searched: ScienceDirect, Ingenta Connect, SpringerLink and Wiley Online Library. In these online databases the same search terms were used as a full text search and as a citation search. The abstract databases Web of Knowledge and Scopus were searched, using the above terms as a text word search, and using key papers in a reverse citation search. Finally, a number of journals were hand-searched and several experts contacted. We excluded studies where the event rate was measured in the general population rather than in those with cardiovascular disease. ${ }^{41}$ Where 30-day and 365-day mortality rates were cited, we examined only 365 -day rates. Data were extracted using a standard form (available from the authors on request) by A.J.M. and checked by D.L.

\section{Meta-analysis}

We used summary meta-analysis, pooling hazard ratios where reported. All hazard ratios were entered adjusted rather than unadjusted (where reported and except where indicated). Odds ratios were converted into relative risks (hazard ratios) using the reported control event rate. ${ }^{42}$ Confidence intervals were obtained from all studies or calculated from the data provided.
Heterogeneity was reduced by stratifying using type of mental illness and procedure type; despite this, heterogeneity (defined by $I^{2}$ ) remained high and so random effects meta-analysis was preferred. We required a minimum of three independent studies to justify pooling by procedure type. Any potential sources of bias were reported. Publication bias was assessed using the Begg-Mazumdar statistic. ${ }^{43}$

\section{Results}

The initial PubMed search generated 572 hits. Of these, only 16 discussed cardiac procedures and 58 discussed mortality (online data supplement). Searches in the four full-text collections generated 1572 hits (Fig. 1). Using these strategies we identified 241 references of interest but only 74 were primary data studies. After excluding studies with no relevant outcome, no comparison group or other methodological issues, we identified 9 papers relating to cardiac procedures following acute coronary syndrome and 6 papers relating to mortality following acute coronary syndrome.

\section{Studies examining procedure rate after acute coronary syndrome}

Our search identified 9 publications relating to cardiac procedures following acute coronary syndrome and contained in these reports were 22 analyses using broadly defined mental disorder or severe mental illness and 10 using an adequate definition of schizophrenia or related psychosis (online Table DS1). There was no evidence of publication bias using the Begg-Mazumdar statistic (Fig. DS1). The total sample size was 825754 (mean 91750 , s.d. $=120158$ ). Druss et al examined cardiovascular care following an acute myocardial infarction. ${ }^{44}$ After adjusting for demographic, clinical, hospital and regional factors, those with mental disorders were only $41 \%$ (for schizophrenia) to $78 \%$ (for substance use) as likely to undergo cardiac catheterisation as those without mental disorder. In a further study, Druss et al found patients hospitalised for myocardial infarction with mental health diagnoses were less likely to have reperfusion conducted. ${ }^{45}$ Young \& Foster identified people with mental illness who had experienced a myocardial infarction: this group had significantly lower levels of all three revascularisation procedures - cardiac catheterisation, percutaneous transluminal coronary angioplasty (PTCA) and coronary artery bypass graft (CABG) - compared with those without mental illness, with the lowest rates seen in those over 64 years old. ${ }^{46}$ Petersen et al examined the records of 4340 male veterans discharged after a clinically confirmed myocardial infarction: those with mental illness were less likely to have undergone in-patient diagnostic angiography (age-adjusted RR $=0.90,95 \%$ CI $0.83-0.98$ ) but there was no difference in CABG. ${ }^{47}$ Kisely et al carried out a population-based record-linkage analysis of related data from 1995 through 2001 compared with the general public for each outcome $(n=215889)$ : in psychiatric in-patients the adjusted rate ratios for cardiac catheterisation, PTCA and CABG were 0.41, 0.22 and 0.34 respectively. ${ }^{48}$ However, Plomondon et al found no difference in cardiac procedure rates after acute coronary syndromes presenting to Veterans Health Administration (VHA) hospitals. ${ }^{49}$ Similarly, Jones \& Carney found no difference in the rates of revascularisation. ${ }^{50}$ Laursen et al followed 605649 patients admitted with heart disease in Denmark between 1994 and 2007: people with admissions for severe mental disorder had higher mortality rates from heart disease following cardiac procedures but received lower rates of cardiac revascularisation. ${ }^{51}$ Abrams et al examined the rate of PCI or CABG within 30 days of 


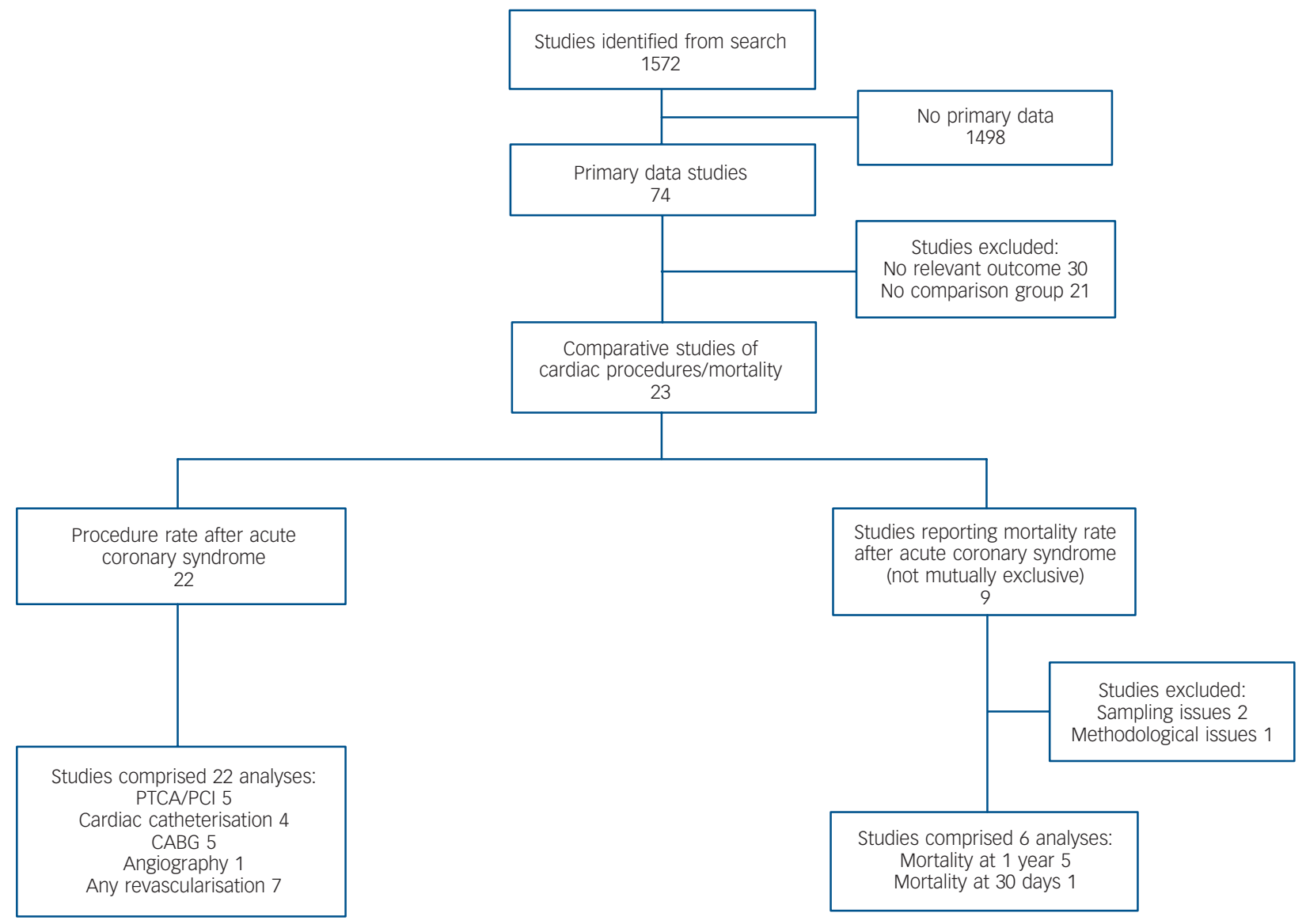

Fig. 1 Study selection. CABG, coronary artery bypass graft; PCl, percutaneous coronary intervention; PTCA, percutaneous transluminal coronary angioplasty.

admission. ${ }^{52}$ They examined mixed mental disorders, defined by ICD-9 codes, in 21745 patients admitted following acute myocardial infarction. They reported results in two related samples: patients with psychiatric comorbidity had lower receipt of coronary revascularisation (hazard ratio, $\mathrm{HR}=0.92,95 \% \mathrm{CI}$ $0.85-0.99)$ in the out-patient sample but equal rates $(\mathrm{HR}=1.00$, $95 \%$ CI $0.91-1.1$ ) in the in-patient sample. ${ }^{52}$

\section{Quantitative differences in procedure rates}

For those with mental illness or severe mental illness there was significant heterogeneity $(I=98.1 \%)$. The meta-analytic random effects size was 0.86 (95\% CI $0.80-0.92, P<0.0001)$, suggesting that those with any mental illness received a $14 \%$ lower rate of cardiac procedures (Fig. 2). Looking at each procedure individually, there was significantly lower receipt of CABG $(\mathrm{RR}=0.85, \quad 95 \% \quad \mathrm{CI} \quad 0.72-1.00)$, cardiac catheterisation $(\mathrm{RR}=0.85,95 \% \mathrm{CI} 0.76-0.95)$ and PTCA/PCI $(\mathrm{RR}=0.87,95 \%$ CI $0.72-1.05)$. For those with schizophrenia there was moderate heterogeneity $(I=77.6 \%)$. The meta-analytic relative risk was 0.53 (95\% CI $0.44-0.64, P<0.0001$ ), suggesting that those with schizophrenia received about half the comparable rate of cardiac procedures (Fig. 3). Looking at each procedure individually, there was significantly lower receipt of $\mathrm{CABG}(\mathrm{RR}=0.69,95 \%$ CI $0.55-0.85)$ and PTCA/PCI ( $\mathrm{RR}=0.50,95 \%$ CI $0.34-0.75)$.

\section{Studies examining mortality after acute coronary syndrome}

We identified ten studies relating to mortality following cardiac events but two reported mortality as the general population rate, one had a significant methodological issue and one had insufficient data for analysis. The total sample size from six valid studies was 596368 (mean 99394, s.d. $=132$ 344). In Druss et al's 2000 study, patients with mental disorders had a small but statistically significantly lower risk of mortality at baseline, and in unadjusted analysis $12.8 \%$ of those with schizophrenia died within 30 days compared with $10.8 \%$ in the comparator population; however, this was not significant after adjustments. ${ }^{44}$ Yet in their replication study, Druss et al found that mental disorder of all types was associated with a 19\% increase in mortality at 1 year. ${ }^{45}$ Importantly, when the five quality indicators were added to the model the association was no longer significant, suggesting that elevated mortality is related to poor quality of care. Petersen et al examined the records of 4340 male veterans discharged after a clinically confirmed myocardial infarction and found a trend towards higher rate of death at 1 year in those with mental illness; the risk of death within 1 year was 1.25 (95\% CI 1.00-1.53). ${ }^{47}$ Plomondon et al studied 14194 patients (including $18 \%$ with severe mental illness) with acute coronary syndromes presenting to VHA hospitals between October 2003 and September $2005 .{ }^{49}$ One-year mortality was lower for patients with severe mental illness $(15.8 \%$ v. $19.1 \%, P<0.001)$. However, in multivariable analysis there was no significant difference in mortality (HR $=0.91,95 \%$ CI $0.81-1.02)$ between patients with and without severe mental illness. ${ }^{49}$

Four additional studies were noteworthy but could not be entered into the meta-analysis. Young \& Foster found that in the older cohort ( $\geqslant 65$ years old) with mental illness there was a $21 \%$ lower risk-adjusted likelihood of death $(P<0.001)$ compared 
Angiography (Petersen, 2003) ${ }^{47}$

Any revascularisation, IP (Abrams, 2009) $)^{52}$

Any revascularisation, OP (Abrams, 2009) ${ }^{52}$

Any revascularisation, eligible subgroup (Druss, 2001) (5 $^{45}$

Any revascularisation, ideal subgroup (Druss, 2001) ${ }^{45}$

Any revascularisation (Kisely, 2007) ${ }^{48}$

Any revascularisation (Laursen, 2009) ${ }^{51}$

Any revascularisation (Petersen, 2003) ${ }^{47}$

CABG (Druss, 2000) ${ }^{44}$

CABG (Jones, 2005) $)^{50}$

CABG (Plomondon, 2007) $)^{49}$

CABG, younger subgroup (Young, 2000) $)^{46}$

CABG, older subgroup (Young, 2000) ${ }^{46}$

CC (Druss, 2000) ${ }^{44}$

CC (Plomondon, 2007) ${ }^{49}$

CC (Young, 2000) ${ }^{46}$

CC (Young, 2000) $)^{46}$

PTCA/PCI (Plomondon, 2007) ${ }^{49}$

PTCA (Druss, 2000) ${ }^{44}$

PTCA (Jones, 2005) $)^{50}$

PTCA (Young, 2000) ${ }^{46}$

PTCA (Young, 2000) $)^{46}$

Combined

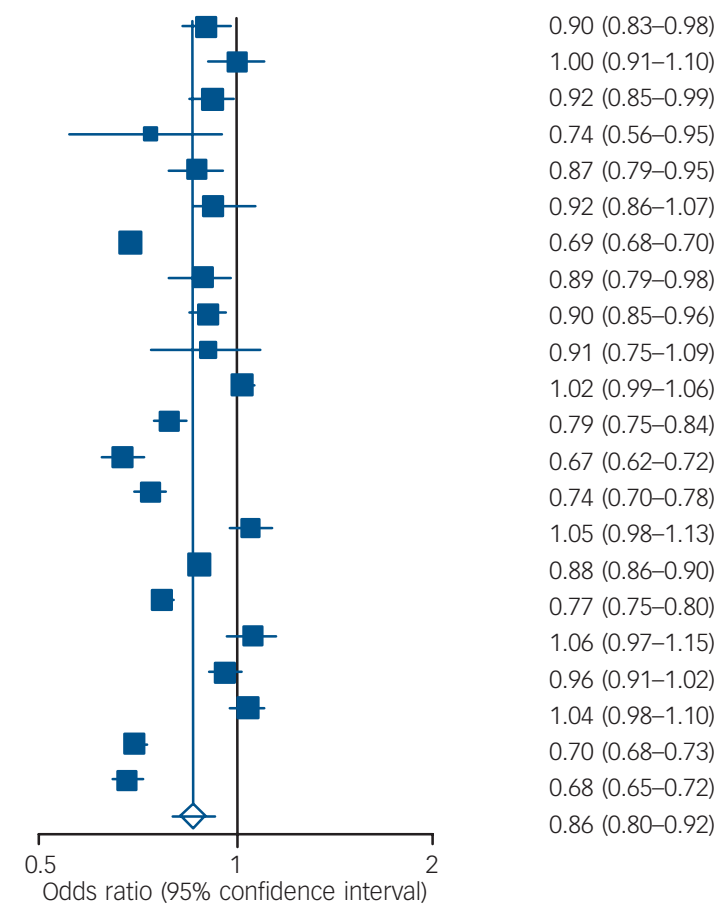

Fig. 2 Meta-analytic summary for receipt of cardiac procedures in patients with mental ill health $v$. those with no mental illness. CABG, coronary artery bypass graft; CC, cardiac catheterisation; IP, in-patient; OP, out-patient; PTCA, percutaneous transluminal coronary angioplasty; $\mathrm{PCl}$, percutaneous coronary intervention.

with those without mental illness. ${ }^{46}$ In the younger cohort those with schizophrenia and substance misuse had higher in-patient mortality rates (both $P<0.001$ ). Unfortunately, data were inadequately reported for extraction. Kisely et al examined mortality and revascularisation in a general population sample. ${ }^{48}$ They conducted a population-based record-linkage analysis of related data from 1995 through 2001 compared with the general population for each outcome $(n=215889)$ : the age-standardised mortality rate ratio for psychiatric patients was 1.31 (95\% CI

Any revascularisation, men (Lawren
Any revascularisation, women (Lawra
CABG (Jones, 2005)
CABG, age $<65($ Young, 2000)
CABG, age $\geqslant 65(\text { Young, 2000) })^{46}$
CC, age $\geqslant 65\left(\right.$ Young, 2000) ${ }^{46}$
CC, age $<65\left(\right.$ Young, 2000) ${ }^{46}$
PTCA (Jones, 2005$)^{50}$
PTCA, age $<65\left(\right.$ Young, 2000) ${ }^{46}$
PTCA, age $\geqslant 65(\text { Young, 2000) })^{46}$
Combined

1.25-1.36). In the study from Lawrence et al, ischaemic heart disease was the major cause of excess mortality in psychiatric patients. ${ }^{41}$ The standardised mortality rate from ischaemic heart disease in mental health users was almost twice that in the overall population (1.91 in total ischaemic heart disease, 1.74 in acute myocardial infarction). However, in the latter two studies the risk was measured at the population level, not specifically in those with acute coronary syndrome. Recently, Blecker et al examined mortality in 341 individuals with heart failure and severe mental

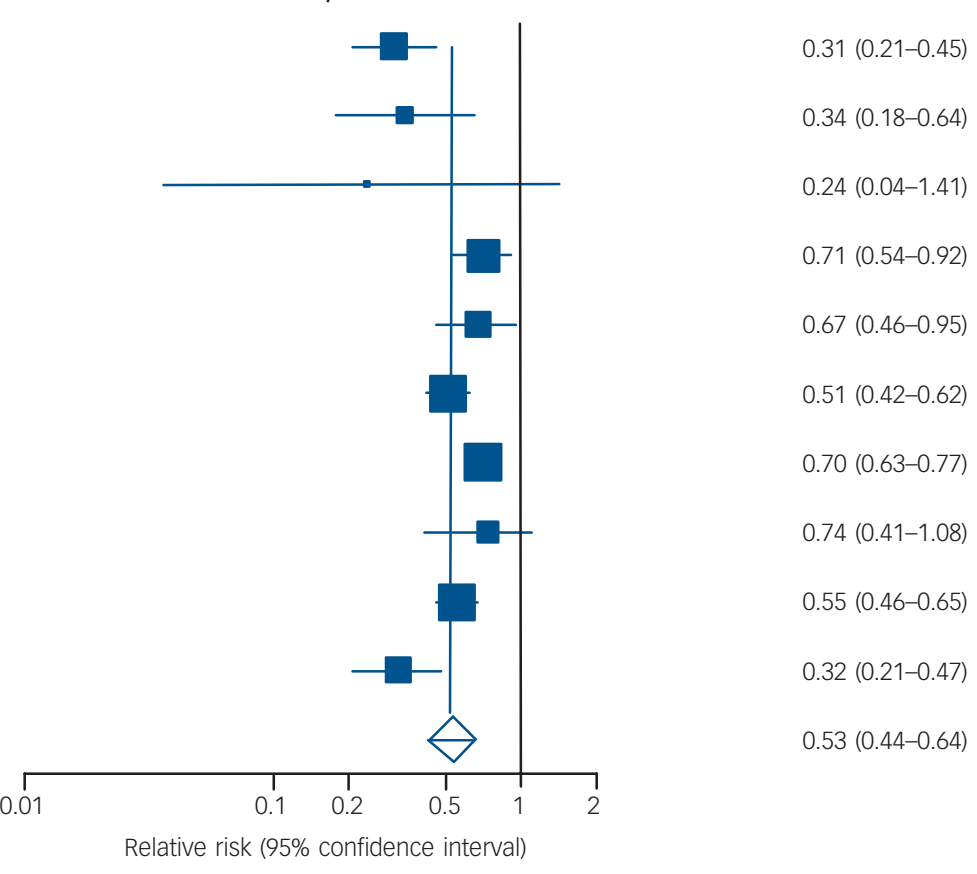

Fig. 3 Meta-analytic summary for receipt of cardiac procedures in patients with schizophrenia v. those with no mental illness. CABG, coronary artery bypass graft; CC, cardiac catheterisation; PTCA, percutaneous transluminal coronary angioplasty. 


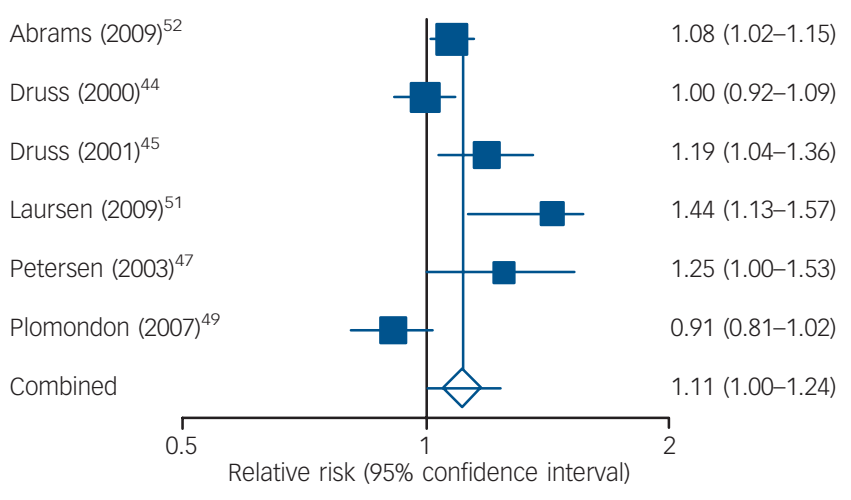

Fig. 4 Meta-analytic summary of mortality rates following acute coronary syndrome in patients with mental illness $v$. those with no mental illness.

illness compared with 1460 with heart failure and no severe mental illness. ${ }^{53}$ Mortality was $29.9 \%$ in the severe mental illness group compared with $31.7 \%$ in those without severe mental illness. However, we excluded this study from the meta-analysis because it was not clear whether the follow-up period was identical in the two groups.

\section{Quantitative differences in mortality following acute coronary syndrome}

For those with severe mental illness there was significant heterogeneity $(I=91.6 \%)$, therefore random effects meta-analysis was preferred. The pooled relative risk for mortality was 1.15 (95\% CI 1.02-1.29). Excluding the studies by Kisely et al and Lawrence et al which did not focus on acute coronary syndrome, the pooled relative risk for mortality was 1.11 (95\% CI 1.00-1.24; $P=0.05)$, suggesting an $11 \%$ increase in mortality rates (Fig. 4).

\section{Discussion}

It is already known that people with depression have higher than expected mortality after myocardial infarction. ${ }^{54,55}$ We also know that background cardiovascular mortality in those with schizophrenia or severe mental illness is at least double the expected rate. ${ }^{27,39,56-60}$ Here, we extend these findings to a population with established acute coronary syndrome, largely myocardial infarction. Pooled results suggest an $11 \%$ increase in comparator mortality rates in those with severe mental illness. This is lower than previously documented in depression but nevertheless statistically significant. We also extend previous narrative reviews that highlighted inferior quality of medical care. $^{12,16}$ From 22 analyses of coronary interventions following serious cardiac events, we found that those with defined mental disorder received $86 \%$ of comparable procedures with significantly lower receipt of CABG, cardiac catheterisation and PTCA/PCI. From 10 analyses, people with a diagnosis of schizophrenia or related psychosis received only 0.53 of the usual procedure rate, with significantly lower receipt of CABG and PTCA/PCI. One possible explanation is that physicians do not offer procedures to those with mental illness because they believe that such individuals are likely to have poorer uptake of care. However, findings regarding uptake of medical care are conflicting. ${ }^{12}$ Another possibility is that the needs of those with mental illness are crowded out by the focus on mental concerns or possibly other medical factors, which may lead physicians to think that procedures are not a priority in this group. There is also a question whether people with severe mental illness follow through with advice they are given. These questions can only be answered by good-quality studies examining physician responses to unmet medical needs in those with mental ill health as well as follow-up of patient behaviour.

\section{Possible mechanisms underlying elevated mortality rates}

In the general population prolonged $\mathrm{QT}_{\mathrm{c}}$ interval and low heart rate variability have been associated with increased cardiovascular mortality and sudden death, particularly in people with prior cardiovascular disease and diabetes. ${ }^{61,62}$ Schizophrenia appears to be associated with similar QT abnormalities, possibly even in the absence of antipsychotic medication, and it is possible that these factors are influential following acute coronary syndrome. ${ }^{63-65}$ It is also well known that metabolic syndrome and diabetes increase the risk of mortality, ${ }^{66,67}$ and these conditions are often more common in those with severe mental illness. There is also a higher rate of sudden cardiac death in those taking antipsychotics; ${ }^{68}$ that said, sudden cardiac death accounts for only a small proportion of excess mortality in schizophrenia. ${ }^{69}$ Unfortunately none of the studies cited here examined use of psychotropic drugs. A second mechanism might be the influence of severe mental illness on the effectiveness of cardiac treatment, for example through low engagement in rehabilitation. Preliminary evidence suggests similar uptake but lower completion of physical exercise programmes in those with known mental ill health. ${ }^{70}$ Confounding factors such as alcohol and drug use and medical comorbidities may also be influential. Most concerning is whether deficits in quality of care influence high mortality in this population. Li et al analysed New York's publicly released Cardiac Surgery Report of surgeons' risk-adjusted mortality rates. ${ }^{71}$ After adjustments, patients with both substance use and psychiatric disorders were more likely to receive care from surgeons in the high-mortality group $(\mathrm{OR}=1.76, P=0.024)$. Druss et al found that the excess mortality following myocardial infarction was negated when five quality measures were added to the model, suggesting that poor quality of care may be an important explanatory variable. ${ }^{45}$ More recently, Copeland et al analysed whether patients' reduced primary care use over time was a significant predictor of mortality over a 4-year period among VHA patients; those with schizophrenia were likely to have low primary care use decreasing with time, and this was linked with inferior survival. $^{72}$

Despite the large sample size we acknowledge several limitations in this meta-analysis. Our results may not be representative of all healthcare systems as all studies following acute coronary syndrome originated in the USA. It is not clear that inequalities would exist in other healthcare systems where there are fewer barriers to care for those who are most socially disadvantaged. One limitation is that the definition of severe mental illness varied in some studies, and although most used ICD-8 or ICD-9 coding the definition employed by one group was not entirely clear. ${ }^{44} \mathrm{~A}$ second limitation is that all studies were retrospective and none distinguished current from historical mental ill health and thus it is uncertain if risk applies to those with prior as well as current diagnoses. A third limitation in relation to mortality was that the studies by Lawrence et al and Kisely et al reported risk in population samples not specifically following acute coronary syndrome and were therefore excluded from the analysis. ${ }^{41,48}$ Additionally, Druss et al and Young \& Foster did not report 1 -year mortality rates, ${ }^{4,46}$ adding to the heterogeneity in mortality analysis. Finally, there was poor data 
quality regarding hospitalisation and patient-provider factors underlying poor outcomes.

\section{Improving inequalities in cardiac care}

The disparities in cardiac care noted here are consistent with the wider literature documenting disparities in treatment of other medical domains including diabetes, general medicine and cancer care. $^{12,73,74}$ Individuals with schizophrenia and severe mental illness receive as little as half of the monitoring offered to people without mental ill health. ${ }^{75,76}$ For example, in the Clinical Antipsychotic Trials of Intervention Effectiveness (CATIE) study, patients with schizophrenia had limited access to or received suboptimal medical care. ${ }^{77}$ In a retrospective analysis of 1998 2003 Medicaid claims, fewer than $20 \%$ of people starting treatment with antipsychotic medication received baseline glucose testing and fewer than $10 \%$ received baseline lipid testing. ${ }^{78}$ Unfortunately, professional responsibility for comorbid medical disorders is often unclear. Poor mental health status is linked with poor general practitioner accessibility and perceived barriers to medical treatment. ${ }^{79}$ Hence medical comorbidity often is overlooked in those with severe mental illness, with up to half of all chronic conditions remaining unrecognised. ${ }^{80-84}$ Yet there is great interest in effective interventions that might reduce cardiovascular mortality in schizophrenia as well as in mental illness in general. Several groups have developed screening and monitoring guidelines. ${ }^{85-88}$ However, implementation of these has been inconsistent. ${ }^{89-93}$ In the general population lifestyle interventions can significantly influence mortality. ${ }^{94}$ In diabetes glycaemic control has similar benefits. The magnitude of the effect of intensive glycaemic control in diabetes is of the same order as the excess risk documented here. ${ }^{67}$ Interventions specifically targeting weight control and eating habits in people with chronic mental illness have shown some promising results. ${ }^{95-99}$ However, it is uncertain if benefits are maintained and whether there is any measurable effect on mortality. Ultimately it has been suggested that a reorganisation of mental health services would help redefine responsibility for physical health. ${ }^{100}$ There is some support for a collaborative model of care, co-locating psychiatric and primary care. ${ }^{101}$ Yet to improve cardiac care in severe mental illness, interventions must be effective at the secondary-care level for hospital specialists with limited interest in mental illness.

In conclusion, following cardiac events individuals with mental illness appear to receive about $14 \%$ less frequent therapeutic cardiac procedures ( $47 \%$ in the case of schizophrenia), and they have about an $11 \%$ increased mortality rate. Further work is required to explore whether these factors are causally linked and whether improvements in medical care might improve survival in those with mental ill health.

Alex J. Mitchell, MBBS, Department of Liaison Psychiatry, Leicestershire Partnership Trust and Department of Cancer Studies and Molecular Medicine, Leicester Royal Infirmary, Leicester, UK; David Lawrence, PhD, Telethon Institute for Child Health Research, Centre for Child Health Resaerch, The University of Western Australia, Perth, Australia

Correspondence: Alex J. Mitchell, Department of Liaison Psychiatry, Leicester General Hospital, Leicester LE5 4PW, UK. Email: Alex.mitchell@leicspart.nhs.uk

First received 22 Dec 2009, final revision 23 Sep 2010, accepted 21 Oct 2010

\section{References}

1 Lopez AD, Mathers CD, Ezzati M, Jamison DT, Murray CJL (eds) Global Burden of Disease and Risk Factors. World Bank, 2006
2 Murray CJL, Lopez AD. The Global Burden of Disease: A Comparative Assessment of Mortality and Disability from Diseases, Injuries, and Risk Factors in 1990 and Projected to 2020, vol 1. Harvard University Press, 1996.

3 Anderson JL, Adams CD, Antman EM, Bridges CR, Califf RM, Casey DE, et al. ACC/AHA 2007 guidelines for the management of patients with unstable angina/non ST-elevation myocardial infarction: a report of the American College of Cardiology/American Heart Association Task Force on Practice Guidelines. Circulation 2007: 116: 148-304.

4 Alpert JS, Thygesen $\mathrm{K}$, Antman E, Bassand JP. Myocardial infarction redefined - a consensus document of the Joint European Society of Cardiology/ American College of Cardiology Committee for the redefinition of myocardial infarction. J Am Coll Cardiol 2000; 36: 959-69.

5 Hunink MG, Goldman L, Tosteson AN, Mittleman MA, Goldman PA, Williams $\mathrm{LW}$, et al. The recent decline in mortality from coronary heart disease, 19801990: the effect of secular trends in risk factors and treatment. JAMA 1997; 277: 535-42.

6 Alter DA, Naylor CD, Austin P, Tu JV. Effects of socioeconomic status on access to invasive cardiac procedures and on mortality after acute myocardial infarction. N Engl J Med 1999; 341: 1359-67.

7 Morris RW, Whincup PH, Papacosta O, Walker M, Thomson A. Inequalities in coronary revascularisation during the 1990s: evidence from the British regional heart study. Heart 2005; 91: 635-40.

8 Rasmussen JN, Rasmussen S, Gislason GH, Abildstrom SZ, Schramm TK, Torp-Pedersen $\mathrm{C}$, et al. Persistent socio-economic differences in revascularization after acute myocardial infarction despite a universal health care system - a Danish study. Cardiovasc Drugs Ther 2007; 21: 449-57.

9 Sekhri N, Timmis A, Chen R, Junghans C, Walsh N, Zaman MJ, et al. Inequity of access to investigation and effect on clinical outcomes: prognostic study of coronary angiography for suspected stable angina pectoris. BMJ 2008; 336: $1058-61$.

10 Rosvall M, Chaix B, Lynch J, Lindström M, Merlo J. The association between socioeconomic position, use of revascularization procedures and five-year survival after recovery from acute myocardial infarction. BMC Public Health 2008; 8: 44

11 Quatromoni J, Jones R. Inequalities in socio-economic status and invasive procedures for coronary heart disease: a comparison between the USA and the UK. Int J Clin Pract 2008; 62: 1910-9.

12 Mitchell AJ, Malone D, Carney Doebbeling C. Quality of medical care for people with and without comorbid mental illness and substance misuse: systematic review of comparative studies. Br J Psychiatry 2009; 194: 491-9.

13 Lord OL, Malone D, Mitchell AJ. Quality of preventive care for people with and without comorbid mental illness systematic review of comparative studies. Gen Hosp Psychiatry 2010; 32: 519-43.

14 Fleischhacker wW, Cetkovich-Bakmas $\mathrm{M}$, De Hert $\mathrm{M}$, Hennekens $\mathrm{CH}$, Lambert M, Leucht S, et al. Comorbid somatic illnesses in patients with severe mental disorders: clinical, policy, and research challenges. J Clin Psychiatry 2008; 69: 514-9.

15 Hennekens $\mathrm{CH}$, Hennekens AR, Hollar D, Casey DE. Schizophrenia and increased risks of cardiovascular disease. Am Heart J 2005; 150: 1115-21.

16 Unützer J, Schoenbaum, M, Druss BG, Katon WJ. Transforming mental health care at the interface with general medicine: report for the President's Commission. Psychiatr Serv 2006; 57: 37-47.

17 De Hert M, Dekker JM, Wood D, Kahl KG, Holt RI, Möller HJ. Cardiovascular disease and diabetes in people with severe mental illness position statement from the European Psychiatric Association (EPA), supported by the European Association for the Study of Diabetes (EASD) and the European Society of Cardiology (ESC). Eur Psychiatry 2009; 24: 412-24.

18 National Institute for Health and Clinical Excellence. Schizophrenia: Core Interventions in the Treatment and Management of Schizophrenia in Adults in Primary and Secondary Care (update). NICE, 2009 (http://www.nice.org.uk/ Guidance/CG/WaveR/26).

19 Sáiz Ruiz J, Bobes García J, Vallejo Ruiloba J, Giner Ubago J, García-Portilla González MP, et al. Consensus on physical health of patients with schizophrenia from the Spanish Societies of Psychiatry and Biological Psychiatry. Actas Esp Psiquiatr 2008; 36: 251-64.

20 Suvisaari JM, Saarni SI, Perälä J, Suvisaari JVJ, Härkänen T, Lönnqvist J, et al. Metabolic syndrome among persons with schizophrenia and other psychotic disorders in a general population survey. J Clin Psychiatry 2007; 68: 1045-55.

21 McEvoy JP, Meyer JM, Goff DC, Nasrallah HA, Davis SM, Sullivan L, et al. Prevalence of the metabolic syndrome in patients with schizophrenia: baseline results from the Clinical Antipsychotic Trials of Intervention Effectiveness (CATIE) schizophrenia trial and comparison with national estimates from NHANES III. Schizophr Res 2005; 80: 19-32.

22 Filik R, Sipos A, Kehoe PG, Burns T, Cooper SJ, Stevens $\mathrm{H}$, et al. The cardiovascular and respiratory health of people with schizophrenia. Acta Psychiatr Scand 2006; 113: 298-305. 
23 Casey DE, Haupt DW, Newcomer JW, Henderson DC, Sernyak MJ, Davidson $\mathrm{M}$, et al. Antipsychotic-induced weight gain and metabolic abnormalities: implications for increased mortality in patients with schizophrenia. $J$ Clin Psychiatry 2004; 65 (suppl 7): 4-18.

24 Sundquist $\mathrm{K}$, Li X. Alcohol abuse partly mediates the association between coronary heart disease and affective or psychotic disorders: a follow-up study in Sweden. Acta Psychiatr Scand 2006; 113: 283-9.

25 Kilbourne AM, Cornelius JR, Han X, Haas GL, Salloum I, Conigliaro J, et al. General-medical conditions in older patients with serious mental illness. Am J Geriatr Psychiatry 2005; 13: 250-4.

26 Suvisaari J, Jonna Perälä J, Saarni SI, Kattainen A, Lönnqvist J, Reunanen A Coronary heart disease and cardiac conduction abnormalities in persons with psychotic disorders in a general population. Psychiatry Res 2010; 175 126-32.

27 Osborn DP, Levy G, Nazareth I, Petersen I, Islam A, King MB. Relative risk of cardiovascular and cancer mortality in people with severe mental illness from the United Kingdom's General Practice Research Database. Arch Gen Psychiatry 2007; 64: 242-9.

28 Laursen TM, Munk-Olsen T, Nordentoft M, Mortensen PB. Increased mortality among patients admitted with major psychiatric disorders: a register-based study comparing mortality in unipolar depressive disorder, bipolar affective disorder, schizoaffective disorder, and schizophrenia. J Clin Psychiatry 2007 68: 899-907.

29 McDermott S, Moran R, Platt T, Isaac T, Wood H, Dasari S. Heart disease, schizophrenia, and affective psychoses: epidemiology of risk in primary care. Commun Ment Health J 2005; 41: 747-55.

30 Curkendall SM, Mo J, Glasser DB, Stang MR, Jones JK. Cardiovascular disease in patients with schizophrenia in Saskatchewan, Canada. J Clin Psychiatry 2004; 65: 715-20.

31 De Leon J, Diaz FJ. A meta-analysis of worldwide studies demonstrates an association between schizophrenia and tobacco smoking behaviors. Schizophr Res 2005; 76: 135-57.

32 Allison DB, Fontaine KR, Heo M, Mentore JL, Cappelleri JC, Chandler LP, et al. The distribution of body mass index among individuals with and without schizophrenia. J Clin Psychiatry 1999; 60: 215-20.

33 Heiskanen T, Niskanen L, Lyytikainen R, Saarinen PI, Hintikka J. Metabolic syndrome in patients with schizophrenia. J Clin Psychiatry 2003; 64: 575-9.

34 Daumit GL, Goldberg RW, Anthony C, Dickerson F, Brown CH, Kreyenbuhl J, et al. Physical activity patterns in adults with severe mental illness. I Nerv Ment Dis 2005; 193: 641-6.

35 Goff DC, Sullivan LM, McEvoy JP, Meyer JM, Nasrallah HA, Daumit GL, et al. A comparison of ten-year cardiac risk estimates in schizophrenia patients from the CATIE study and matched controls. Schizophr Res 2005; 80: 45-53.

36 Osborn DPJ, Wright CA, Levy G, King MB, Deo R, Nazareth I. Relative risk of diabetes, dyslipidaemia, hypertension and the metabolic syndrome in people with severe mental illnesses: systematic review and metaanalysis. BMC Psychiatry 2008; 8: 84

37 Grundy SM, Pasternak R, Greenland P, Smith S, Fuster R. Assessment of cardiovascular risk by use of multiple-risk-factor assessment equations: a statement for healthcare professionals from the American Heart Association and the American College of Cardiology. Circulation 1999; 100: 1481-92.

38 Brown S. Excess mortality of schizophrenia. A meta-analysis. Br J Psychiatry 1997; 171: 502-8.

39 Saha S, Chant D, McGrath J. A systematic review of mortality in schizophrenia: is the differential mortality gap worsening over time? Arch Gen Psychiatry 2007; 64: 1123-31.

40 Moher DM, Liberati A, Tetzlaff J, Altman DG. Preferred reporting items for systematic reviews and meta-analyses: the PRISMA statement. BMJ 2009; 339: 2535.

41 Lawrence DM, Holman CDJ, Jablensky AV, Hobbs MST. Death rate from ischaemic heart disease in Western Australian psychiatric patients 1980-1998. Br J Psychiatry 2003; 182: 31-6.

42 Zhang JM, Yu KF. What's the relative risk? A method of correcting the odds ratio in cohort studies of common outcomes. JAMA 1998; 280: 1690-1.

43 Begg $\mathrm{CB}$, Mazumdar M. Operating characteristics of a rank correlation test for publication bias. Biometrics 1994; 50: 1088-101.

44 Druss BG, Bradford DW, Rosenheck RA, Radford MJ, Krumholz HM. Mental disorders and use of cardiovascular procedures after myocardial infarction. JAMA 2000; 283: 506-11.

45 Druss BG, Bradford WD, Rosenheck RA, Radford MJ, Krumholz HM. Quality of medical care and excess mortality in older patients with mental disorders. Arch Gen Psychiatry 2001; 58: 565-72.

46 Young J, Foster D. Cardiovascular procedures in patients with mental disorders. JAMA 2000; 283: 3198-9.
47 Petersen LA, Normand SL, Druss BG, Rosenheck RA. Process of care and outcome after acute myocardial infarction for patients with mental illness in the VA health care system: are there disparities? Health Serv Res 2003; 38: 41-63.

48 Kisely S, Smith M, Lawrence D, Cox M, Campbell LA, Maaten S. Inequitable access for mentally ill patients to some medically necessary procedures. CMAJ 2007; 176: 779-84.

49 Plomondon ME, Ho PM, Wang L, Greiner GT, Shore JH, Sakai JT, et al. Severe mental illness and mortality of hospitalized ACS patients in the VHA. BMC Health Serv Res 2007; 7: 146.

50 Jones LE, Carney CP. Mental disorders and revascularisation procedures in a commercially insured sample. Psychosom Med 2005; 67: 568-76.

51 Laursen TM, Munk-Olsen T, Agerbo E, Gasse C, Mortensen PB. Somatic hospital contacts, invasive cardiac procedures and mortality from heart disease in patients with severe mental disorder. Arch Gen Psychiatry 2009; 66: 713-20.

52 Abrams TE, Vaughan-Sarrazin M, Rosenthal GE. Psychiatric comorbidity and mortality after acute myocardial infarction. Circ Cardiovasc Qual Outcomes 2009; 2: 213-20.

53 Blecker S, Zhang Y, Ford DE, Guallar E, Dosreis S, Steinwachs DM, et al. Quality of care for heart failure among disabled Medicaid recipients with and without severe mental illness. Gen Hosp Psychiatry 2010; 32: 255-61.

54 Van Melle JP, de Jonge P, Spijkerman TA, Tijssen JG, Ormel J, van Veldhuisen DJ, et al. Prognostic association of depression following myocardial infarction with mortality and cardiovascular events: a meta-analysis. Psychosom Med 2004; 66: 814-22.

55 Nicholson A, Kuper $\mathrm{H}$, Hemingway $\mathrm{H}$. Depression as an aetiologic and prognostic factor in coronary heart disease: a meta-analysis of 6362 events among 146538 participants in 54 observational studies. Eur Heart J 2006; 27 : 2763-74.

56 Newman SC, Bland RC. Mortality in a cohort of patients with schizophrenia: a record linkage study. Can J Psychiatry 1991; 36: 239-45.

57 Brown S, Barraclough B, Inskip H. Causes of the excess mortality of schizophrenia. Br J Psychiatry 2000; 177: 212-7.

58 Osby U, Correia N, Brandt L, Ekbom A, Sparén P. Mortality and causes of death in schizophrenia in Stockholm County, Sweden. Schizophr Res 2000; 45: 21-8.

59 Joukamaa $M$, Heliövaara $M$, Knekt $P$, Aromaa A, Raitasalo R, Lehtinen V. Mental disorders and cause-specific mortality. Br J Psychiatry 2001; 179 498-502.

60 Heilä H, Haukka J, Suvisaari J, Lönnqvist J. Mortality among patients with schizophrenia and reduced psychiatric hospital care. Psychol Med 2005; 35 725-32.

61 Montanez A, Ruskin JN, Hebert PR, Lamas GA, Hennekens CH. Prolonged QTC interval and risks of total and cardiovascular mortality and sudden death in the general population: a review and qualitative overview of the prospective cohort studies. Arch Intern Med 2004; 164: 943-8.

62 Elming H, Brendorp B, Kober L, Sahebzadah N, Torp-Petersen C. QTc interval in the assessment of cardiac risk. Cardiac Electrophysiol Rev 2002; 6: 289-94.

63 Bär K-J, Koschke M, Boettger MK, Berger S, Kabisch A, Sauer H, et al. Acute psychosis leads to increased QT variability in patients suffering from schizophrenia. Schizophr Res 2007; 95: 115-23.

64 Mujica-Parodi LR, Yeragani V, Malaspina D. Nonlinear complexity and spectral analyses of heart rate variability in medicated and unmedicated patients with schizophrenia. Neuropsychobiology 2005; 51: 10-5.

65 Jindal RD, Keshavan MS, Eklund K, Stevens A, Montrose DM, Yeragani VK. Beat-to-beat heart rate and QT interval variability in first episode neurolepticnaive psychosis. Schizophr Res 2009; 113: 176-80.

66 Lakka HM, Laaksonen DE, Lakka TA, Niskanen LK, Kumpusalo E, Tuomilehto J, et al. The metabolic syndrome and total and cardiovascular disease mortality in middle-aged men. JAMA 2002; 288: 2709-16.

67 Ray KK, Rao S, Seshasai K, Sivakumaran R, Nethercott S, Preiss D, et al. Effect of intensive control of glucose on cardiovascular outcomes and death in patients with diabetes mellitus: a meta-analysis of randomised controlled trials. Lancet 2009; 373: 1765-72.

68 Ray WA, Chung CP, Murray KT, Hall K, Stein CM. Atypical antipsychotic drugs and the risk of sudden cardiac death. N Engl J Med 2009; 360: 225-35.

69 Mitchell AJ. Do antipsychotics cost lives or save lives? Risks versus benefits from large epidemiological studies. J Clin Psychopharmacol 2009; 29: 517-9.

70 Crone D, Johnston LH, Gidlow C, Henley C, James DV. Uptake and participation in physical activity referral schemes in the UK: an investigation of patients referred with mental health problems. Issues Ment Health Nurs 2008; 29: 1088-97. 
71 Li Y, Glance LG, Cai X, Mukamel DB. Are patients with coexisting mental disorders more likely to receive CABG surgery from low-quality cardiac surgeons? The experience in New York State. Med Care 2007; 45: 587-93.

72 Copeland LA, Zeber JE, Wang CP, Henley C, James DV, et al. Patterns of primary care and mortality among patients with schizophrenia or diabetes: a cluster analysis approach to the retrospective study of healthcare utilization. BMC Health Serv Res 2009; 9: 127.

73 Desai M, Rosenheck RA, Druss BG, Perlin JB. Mental disorders and quality of diabetes care in the veterans health administration. Am J Psychiatry 2002; 159: $1584-90$

74 Mateen FJ, Jatoi A, Lineberry TW, Aranguren D, Creagan ET, Croghan GA et al. Do patients with schizophrenia receive state-of-the-art lung cancer therapy? A brief report. Psychooncology 2008; 17: 721-5.

75 Roberts L, Roalfe A, Wilson S, Lester H. Physical health care of patients with schizophrenia in primary care: a comparative study. Fam Pract 2007; 24: 34-40.

76 Vahia IV, Diwan S, Bankole AO, Kehn M, Nurhussein M, Ramirez P, et al Adequacy of medical treatment among older persons with schizophrenia. Psychiatr Serv 2008; 59: 853-9.

77 Nasrallah HA, Meyer JM, Goff DC, McEvoy JP, Davis SM, Stroup TS, et al. Low rates of treatment for hypertension, dyslipidemia and diabetes in schizophrenia: data from the CATIE schizophrenia trial sample at baseline. Schizophr Res 2006; 86: 15-22.

78 Morrato EH, Newcomer JW, Allen RR, Valuck RJ. Prevalence of baseline serum glucose and lipid testing in users of second-generation antipsychotic drugs: a retrospective, population-based study of medicaid claims data. J Clin Psychiatry 2008; 69: 316-22.

79 Al-Mandhari AS, Hassan AA, Haran D. Association between perceived health status and satisfaction with quality of care: evidence from users of primary health care in Oman. Fam Pract 2004; 21: 519-27.

80 Kilbourne AM, McCarthy JF, Welsh D, Blow F. Recognition of co-occurring medical conditions among patients with serious mental illness. J Nerv Ment Dis 2006; 194: 598-602.

81 Koranyi E. Morbidity and rate of undiagnosed physical illness in a psychiatric population. Arch Gen Psychiatry 1979; 36: 414-9.

82 Farmer S. Medical problems of chronic patients in a community support program. Psychiatr Serv 1987; 38: 745-9.

83 Fallow S, Bowler C, Dennis M, Jones P. Undetected physical illness in older referrals to a community mental-health-service. Int J Geriatr Psychiatry 1995 10: $74-5$.

84 Bernardo $\mathrm{M}$, Banegas JR, Canas $\mathrm{F}$, Casademot $\mathrm{X}$, Riesgo $\mathrm{Y}$, Varela $\mathrm{C}$. Low level of medical recognition and treatment of cardiovascular risk factors in patients with schizophrenia in Spain. 13th Biennial Winter Workshop on Schizophrenia Research. Schizophr Res 2006; 81: 176-7.

85 American Diabetes Association. Consensus Development Conference on Antipsychotic Drugs and Obesity and Diabetes. Diabetes Care 2004; 27: 596-601.

86 Cohn TA, Sernyak MJ. Metabolic monitoring for patients treated with antipsychotic medications. Can J Psychiatry 2006; 51: 492-501.
87 De Hert M, van Eyck D, De Nayer A. Metabolic abnormalities associated with second generation antipsychotics: fact or fiction? Development of guidelines for screening and monitoring. Int Clin Psychopharmacol 2006; 21 (suppl 2): $11-5$.

88 Waterreus AJ, Laugharne JD. Screening for the metabolic syndrome in patients receiving antipsychotic treatment: a proposed algorithm. Med J Aust 2009; 190: 185-9.

89 Citrome L, Yeomans D. Do guidelines for severe mental illness promote physical health and well-being? J Psychopharmacol 2005; 19: 102-9.

90 Buckley PF, Miller DD, Singer B. Clinicians' recognition of the metabolic adverse effects of antipsychotic medications. Schizophr Res 2005; 79 : 281-8.

91 Haupt DW, Rosenblatt LC, Kim E, Baker RA, Whitehead R, Newcomer JW. Prevalence and predictors of lipid and glucose monitoring in commercially insured patients treated with second-generation antipsychotic agents. Am J Psychiatry 2009; 166: 345-53.

92 Schneiderhan ME, Batscha CL, Rosen C. Assessment of a point-of-care metabolic risk screening program in outpatients receiving antipsychotic agents. Pharmacotherapy 2009; 29: 975-87.

93 Mackin $\mathrm{P}$, Bishop D, Watkinson H. A prospective study of monitoring practices for metabolic disease in antipsychotic-treated community psychiatric patients. BMC Psychiatry 2007; 7: 28.

94 lestra JA, Kromhout D, van der Schouw YT, Grobbee DE, Boshuizen HC, van Staveren WA. Effect size estimates of lifestyle and dietary changes on all cause mortality in coronary artery disease patients: a systematic review. Circulation 2005; 112: 924-34.

95 Khazaal Y, Fresard E, Rabia S, Chatton A, Rothen S, Pomini V, et al. Cognitive behavioural therapy for weight gain associated with antipsychotic drugs. Schizophr Res 2007; 91: 169-77.

96 Pendlebury J, Haddad P, Dursun S. Evaluation of a behavioural weight management programme for patients with severe mental illness: 3 year results. Hum Psychopharmacol 2005; 20: 447-8.

97 Alvarez-Jimenez M, Gonzalez-Blanch C, Vazquez-Barquero JL, Pérez-Iglesias R, Martínez-García O, Pérez-Pardal T, et al. Attenuation of antipsychotic-induced weight gain with early behavioral intervention in drug-naive first-episode psychosis patients: a randomized controlled trial. J Clin Psychiatry 2006; 67: 1253-60.

98 Weber M, Wyne K. A cognitive/behavioral group intervention for weight loss in patients treated with atypical antipsychotics. Schizophr Res 2006; 83: 95-101.

99 Ganguli R. Behavioral therapy for weight loss in patients with schizophrenia. J Clin Psychiatry 2007; 68 (suppl 4): 19-25.

100 Horvitz-Lennon M, Kilbourne AM, Pincus HA. From silos to bridges: meeting the general health care needs of adults with severe mental illnesses. Health Affairs 2006; 25: 659-69.

101 Dombrovski A, Rosenstock J. Bridging general medicine and psychiatry: providing general medical and preventive care for the severely mentally ill. Curr Opin Psychiatry 2004; 17: 523-9. 